\title{
Prior Exposure to Chronic Stress and MDMA Potentiates Mesoaccumbens Dopamine Release Mediated by the $5-\mathrm{HT}_{\text {IB }}$ Receptor
}

\author{
Jennifer L Amato', Michael G Bankson' and Bryan K Yamamoto*,' \\ 'Laboratory of Neurochemistry, Department of Pharmacology, Boston University School of Medicine, Boston, MA, USA
}

\begin{abstract}
(+) 3,4,-Methylenedioxymethamphetamine (MDMA) is an abused drug that acutely releases serotonin (5-HT) and dopamine (DA) but produces long-term damage to 5-HT terminals. MDMA-induced DA release has been shown to be dampened by 5-HT. Although stress also activates the mesolimbic DA pathway, it is unknown if chronic stress after exposure to neurotoxic doses of MDMA will augment MDMA-induced DA release in the nucleus accumbens shell (NAcc(sh)). Rats were pretreated with $M D M A(I 0 m g / k g \times 4$, intraperitoneal (i.p.)). After 7 days, rats were subjected to 10 days of chronic unpredictable stress. DA release in the NAcc(sh) and 5-HT in the ventral tegmental area (VTA) were measured after a challenge injection of MDMA (5 mg/ $/ \mathrm{kg}$, i.p.). The combination of pretreatment with MDMA + stress decreased basal concentrations of 5-HT in the VTA and DA in the NAcc(sh) and enhanced MDMAstimulated DA release in the NAcc(sh). Pretreatment with MDMA or stress alone blunted MDMA-induced 5-HT release in the VTA. The augmentation of MDMA-induced DA release in rats pretreated with MDMA + chronic stress was attenuated by perfusion of the 5-HT IB antagonist, GRI27935 into the VTA before the MDMA challenge injection. These results suggest that prior exposure to both MDMA and stress can produce a long-term augmentation in mesolimbic DA transmission and enhanced drug abuse vulnerability that is mediated, in part, by the 5-HTIB receptor in the VTA.

Neuropsychopharmacology (2007) 32, 946-954. doi:I 0.1038/sj.npp. I 30I 174; published online 2 August 2006
\end{abstract}

Keywords: MDMA; dopamine; serotonin; chronic unpredictable stress; ventral tegmental area; nucleus accumbens shell

\section{INTRODUCTION}

(+ ) 3, 4-Methylenedioxymethamphetamine (MDMA) is a psychostimulant that is abused worldwide. The stimulant and rewarding properties of abused psychostimulants such as MDMA, arise in part, from the release of dopamine from neurons that originate in the ventral tegmental area (VTA) and project to the nucleus accumbens shell (NAcc(sh)) (Hoebel, 1985; Wise and Bozarth, 1985; Koob, 1992). MDMA binds to and reverses the dopamine or serotonin transporters, to produce impulse-independent/ carrier-mediated efflux of dopamine or 5-HT, respectively (Johnson et al, 1991). However, MDMA-induced dopamine release is not entirely carrier mediated and involves an impulse-dependent component that is mediated by $5-\mathrm{HT}$ (Koch and Galloway, 1997; Gudelsky and Nash, 1996). Thus, MDMA-induced dopamine release is both carrier mediated

*Correspondence: Dr BK Yamamoto, Laboratory of Neurochemistry, Department of Pharmacology, L-613, Boston University School of Medicine, 7I5 Albany Street, Boston, MA 02118, USA, Tel: + 1617 638 5662, Fax: + I 617638 5668, E-mail: bkyam@bu.edu

Received 21 March 2006; revised 22 May 2006; accepted 20 June 2006 Online publication: 29 June 2006 at http://www.acnp.org/citations/ Npp062906060 185/default.pdf via the reversal of the dopamine transporter and impulse dependent through the stimulation of dopamine neurons by 5 -HT.

Serotonin neurons from the dorsal raphe nucleus project to the mesolimbic DA cell bodies of the VTA and substantia nigra (Gervais and Rouillard, 2000). Multiple 5-HT receptors are believed to modulate basal (Gervais and Rouillard, 2000; Cameron and Williams, 1994; Doherty and Pickel, 2000; Di Giovanni et al, 2000) and MDMA-induced DA release (Yamamoto et al, 1995; Bankson and Yamamoto, 2004). In particular, activation of $5-\mathrm{HT}_{1 \mathrm{~B}}$ receptors in the VTA produces DA efflux in the nACC (Yan et al, 2005; O'Dell and Parsons, 2004) through inhibition of GABA release in the VTA and the consequent disinhibition of DA neurons (Yan and Yan, 2001a; Cameron and Williams, 1995; Cameron and Williams, 1994). In addition, behavioral studies have shown that mice lacking the $5-\mathrm{HT}_{1 \mathrm{~B}}$ receptor or the administration of the $5-\mathrm{HT}_{1 \mathrm{~B}}$ antagonist GR127935 to rats blocks MDMA-induced hyperactivity (McCreary et al, 1999; Scearce-Levie et al, 1999).

Moderate to high doses of MDMA produce selective damage to 5-HT neurons as evidenced by the reduction of 5-HT transporter binding sites (Battaglia et al, 1987; Schmidt, 1987), 5-HT transporter immunoreactivity, 
(O'Hearn et al, 1988), and reductions of 5-HT content (Schmidt, 1987; O'Hearn et al, 1988) as well as tryptophan hydroxylase activity (Schmidt and Taylor, 1988). It follows that these deficits in mesolimbic 5-HT neurotransmission could alter the interaction of 5-HT with dopamine to affect the stimulant and rewarding effects of a subsequent MDMA administration. In fact, rats exposed to a neurotoxic regimen of MDMA exhibit enhanced sensitivity to MDMAinduced reinstatement of amphetamine self-administration (Morley et al, 2004) and attenuate serotonergic reactivity to a challenge dose of MDMA (Shankaran and Gudelsky, 1999) or fenfluramine (Series et al, 1994). Therefore, damage to 5-HT neurons might enhance vulnerability to the addictive properties of MDMA and other drugs of abuse by altering mesolimbic dopamine function.

Similar to many addictive drugs, stress also affects mesolimbic dopamine neurotransmission by eliciting immediate increases in dopamine and 5-HT release (Kalivas and Duffy, 1995; Abercrombie et al, 1989; Broom and Yamamoto, 2005; Bland et al, 2003). Numerous studies have demonstrated that stressful life events are associated with increased drug addiction in humans (Rhoads, 1983; Kosten et al, 1986; Wilsnack et al, 1997; Najavits et al, 1998) and enhanced self-administration of various drugs of abuse by animals (Piazza and Le, 1998). Thus, chronic stress may enhance mesolimbic functions that mediate reward and drug-seeking behavior. However, at present, no studies have assessed if chronic stress alters the mesolimbic dopamine response to MDMA.

Nothing is known about the combined effects of neurotoxic doses of MDMA and chronic stress exposure on MDMA-induced increases in mesolimbic dopamine and 5-HT or the influence of 5-HT receptors in mediating the impulse-dependent component of MDMA-induced dopamine release. Although several animal models of chronic stress exposure have been used, the chronic unpredictable stress (CUS) paradigm has added validity because the type and time of stress exposures are varied (Katz et al, 1981; Willner et al, 1992; Ortiz et al, 1996) to mimic the exposure to unexpected stressful life events. Moreover, the paradigm is not confounded with learning, adaptation, and tolerance of the hypothalamo-adrenal axis (Herman et al, 1995) typically observed with repeated restraint stress (Bielajew et al, 2002; Lopez et al, 1998). CUS also produces neurochemical changes in the mesolimbic dopamine system, increases place preference for cocaine at low doses, and enhances cocaine-induced locomotor activation (Haile et al, 2001), whereas repeated restraint stress does not affect these measures (Ortiz et al, 1996; Haile et al, 2001).

The present study used in vivo, dual-probe microdialysis to assess changes in mesolimbic responses to MDMA in rats with prior exposure to a neurotoxic regimen of MDMA and/ or CUS. Based on the known ability of stress to enhance drug-seeking behavior, it is predicted that CUS, in combination with a serotonergic lesion produced by prior administration of neurotoxic doses of MDMA, will enhance the effect of a challenge dose of MDMA on NAcc(sh) shell dopamine release. Furthermore, it is posited that the augmentation of mesolimbic dopaminergic responsiveness to a challenge injection of MDMA is mediated by $5-\mathrm{HT}_{1 \mathrm{~B}}$ receptors in the VTA.

\section{MATERIALS AND METHODS}

\section{Subjects}

Male Sprague-Dawley rats (Harlan Sprague-Dawley, Indianapolis, IN, USA) weighing 175-220 $\mathrm{g}$ at the beginning of the experimental procedures were housed in pairs in a temperature controlled environment $\left(21-23^{\circ} \mathrm{C}\right)$ for 5 days before the experiments. Food and water were available ad libitum. Lighting was maintained under a $12 \mathrm{~h}$ light-dark cycle (lights on 0700-1900 hours). All procedures were performed during the light cycle and were carried out in accordance with the National Institutes of Health Guide for the Care and Use of Laboratory Animals and the Boston University IACUC.

\section{Drugs}

MDMA was obtained from the National Institutes of Drug Abuse (NIDA, Research Triangle Park, NC, USA). Doses refer to the weight of the salt. MDMA was administered intraperitoneally (i.p.) in a volume of $1 \mathrm{ml}$ per $\mathrm{kg}$ of body weight. GR127935 (N-[4-methoxy-3-(4-methyl-1-piperizinyl)phenyl]-2'-methyl-4'-(5-methyl-1,2,4-oxadiazole-3-yl)[1, $1^{\prime}$-biphenyl]-carboxamide was purchased from Tocris Cookson (Ellisville, MO)) and used as a selective antagonist for the $5-\mathrm{HT}_{1 \mathrm{~b}}$ receptor since there are no $5-\mathrm{HT}_{1 \mathrm{~d}}$ receptors in the rat mesolimbic system. GR127935 was administered by reverse dialysis in modified Dulbecco's buffered saline (137 mM NaCl, $2.7 \mathrm{mM} \mathrm{KCl}, 0.5 \mathrm{mM} \quad \mathrm{MgCl}_{2}, 8.1 \mathrm{mM}$ $\mathrm{Na}_{2} \mathrm{HPO}_{4}, 1.5 \mathrm{mM} \mathrm{KH} \mathrm{PO}_{4}, 1.2 \mathrm{mM} \mathrm{CaCl} 2$ and $0.5 \mathrm{mM}$ d-glucose, pH 7.4; Sigma Chemical Co.; St Louis, MO).

\section{Pretreatment of MDMA}

After acclimation to the colony room, rats were administered i.p. injections of $0.9 \% \mathrm{NaCl}$ or MDMA $(10 \mathrm{mg} / \mathrm{kg})$ once every $2 \mathrm{~h}$ for a total of four injections. Temperatures were recorded every $2 \mathrm{~h}$, on the off hour of injections, to ensure rats reached hyperthermia (at least $40^{\circ} \mathrm{C}$ ) after MDMA. Temperatures were measured via a rectal probe digital thermometer (Thermalert TH-8; Physitemp Instruments Inc., Clifton, NJ). Rats were monitored over night before they were returned to the colony.

\section{CUS Paradigm}

Seven days after MDMA administration, stressed rats were exposed to stressors that varied by day and time for 10 days (Matuszewich and Yamamoto, 2003). Rats were subjected to the following procedure-Day 11000 hours $50 \mathrm{~min}$ cold room $\left(40^{\circ} \mathrm{C}\right), 1300$ hours 60 min cage rotation; Day 21400 hours $4 \mathrm{~min}$ swim stress, 1800 hours lights on overnight (12 h); Day 30900 hours $3 \mathrm{~h}$ lights off, 1300 hours $60 \mathrm{~min}$ restraint stress; Day 41100 hours 20 min cage rotation, 1800 hours lights on overnight (12 h); Day 51500 hours $20 \mathrm{~min}$ cold room $\left(40^{\circ} \mathrm{C}\right), 1800$ hours isolation housing overnight (12 h); Day 61300 hours 60 min restraint stress, 1800 hours food and water deprivation overnight (12 h); Day 71000 hours 2 h lights off, 1400 hours 3 min swim stress; Day 8 1100 hours $50 \mathrm{~min}$ cold room, 1800 hours lights on overnight $(12 \mathrm{~h})$; Day 91000 hours $30 \mathrm{~min}$ cage rotation, 1300 hours $30 \mathrm{~min}$ cold room $\left(40^{\circ} \mathrm{C}\right)$; Day 100900 hours 
intracranial surgery, 1800 hours food and water deprivation overnight $(12 \mathrm{~h})$.

\section{Surgical Procedures}

Both unstressed and stressed rats underwent intracranial surgery performed on the last day of CUS (Day 10). All rats were anesthetized with a combination of ketamine $(80 \mathrm{mg} /$ $\mathrm{kg}$, i.p.) and xylazine (12 $\mathrm{mg} / \mathrm{kg}$, i.p.) before being placed into a Kopf stereotaxic frame. The skull was exposed and microdialysis probes were slowly lowered into the VTA ( $4.8 \mathrm{~mm}$ posterior, $\pm 0.9 \mathrm{~mm}$ medial to bregma and $9.0 \mathrm{~mm}$ ventral to the brain surface) and ipsilateral nucleus accumbens shell $(\mathrm{NAcc}(\mathrm{sh}))(1.7 \mathrm{~mm}$ anterior, $\pm 0.9 \mathrm{~mm}$ medial to bregma and $7.6 \mathrm{~mm}$ ventral to the brain surface). The probes were constructed as described by Yamamoto and Pehek (1990). Probes had an active/exposed membrane length of $2.0 \mathrm{~mm}$ for those targeted at NAcc(sh) and $1.5 \mathrm{~mm}$ for probes targeted at the VTA. The probes and a male metal connector used to attach the rat to a steel spring cable and liquid swivel were secured to the skull with three stainless steel screws and cranioplast cement (Plastics One Inc., Roanoke, VA).

\section{In Vivo Microdialysis}

The day after probe insertion, modified Dulbecco's phosphate buffered saline medium was pumped through the microdialysis probes with a Harvard Model 22 syringe infusion pump (Hollison, MA, USA) set at a flow rate of $1.5 \mu \mathrm{l} / \mathrm{min}$. A 2-h perfusion period was performed before collecting baseline samples. Dialysate samples from the NAcc(sh) and VTA were then collected every $30 \mathrm{~min}$. Four baseline samples were collected before all rats were injected with an MDMA challenge $(5 \mathrm{mg} / \mathrm{kg}$, i.p.). Samples from the VTA and NAcc(sh) were simultaneously collected for $2.5 \mathrm{~h}$. In some experiments, GR127935 $(1 \mu \mathrm{M})$ was reverse dialyzed through the dialysis probe in the VTA for two baseline measures and throughout the period following the systemic injection of an MDMA challenge $(5 \mathrm{mg} / \mathrm{kg})$.

\section{HPLC Analysis of 5-HT and Dopamine}

Microdialysis samples were assayed for 5-HT and dopamine by high-performance liquid chromatography with electrochemical detection. Separation was achieved with a C18 column $(100 \times 2.0 \mathrm{~mm}, 3 \mu \mathrm{m}$ particle size; Phenomenex, Torrance, CA, USA). The mobile phase for detection of 5 -HT and dopamine and metabolites $(\mathrm{pH} 4.2)$ consisted of $32 \mathrm{mM}$ citric acid, $54.3 \mathrm{mM}$ sodium acetate, $0.074 \mathrm{mM}$ EDTA, $0.215 \mathrm{mM}$ octyl sodium sulfate, and $3 \%$ methanol. Detection was accomplished with a DECADE or Intro ${ }^{\mathrm{R}}$ electrochemical detector (Antec Leyden; GBC Scientific Equipment Inc., Hubbardston, MA) and peaks were analyzed with EZChrom ${ }^{\mathrm{R}}$ Scientific Software Inc. (Pleasanton, CA).

\section{Tissue Content of 5-HT and Dopamine in NAcc}

Twenty-two days after rats were pretreated with MDMA (ie 1 week after dialysis experiments), rats were killed by rapid decapitation and brains were removed and quick frozen on dry ice. Brains were sectioned in $40 \mu \mathrm{m}$ increments using a cryostat microtome $\left(-20^{\circ} \mathrm{C}\right)$, and probe placements were recorded for both NAcc and VTA. Once the probe tract in the NAcc was identified, NAcc tissue at 1.7 anterior to bregma was removed from the frozen coronal section using a 16 ga punch. Samples were stored at $-80^{\circ} \mathrm{C}$ until assayed. Tissues were sonicated in cold $0.25 \mathrm{~N} \mathrm{HClO}_{4}$ and centrifuged at $12000 \mathrm{~g}$ for $20 \mathrm{~min}$. The supernatant was analyzed for 5-HT and dopamine using high-performance liquid chromatography with electrochemical detection as described above. Protein was determined by the Bradford Method using Bradford protein dye (Bio-Rad, Hercules, CA). Concentrations are expressed as picograms (pg) per microgram of protein.

\section{Statistical Analyses}

Two-way ANOVAs and two-way ANOVAs with repeated measures were used to compare rats pretreated with MDMA or saline, stress or no stress, and over time including the time during drug administrations. Tukey's test was used to conduct post hoc analyses for any significant treatments at specific time points. Statistical significance was set at $p<0.05$ for all conditions and experiments. The overall effects of MDMA and/or stress on basal extracellular DA and 5-HT are represented by the average of the four baseline samples taken before MDMA challenge. The overall effects of MDMA and/or stress on MDMA-induced changes in extracellular DA and 5-HT over the $2.5 \mathrm{~h}$ following MDMA challenge are represented by the average cumulative change from baseline. The group differences at specific time points are represented by the timecourse plots of percent average basal concentration of DA or 5-HT.

DA and 5-HT concentrations for the microdialysis studies represent concentrations of neurotransmitter recovered in dialysis fluid and are not actual/absolute extracellular concentrations. Thus, treatments were balanced across all groups and across time to control for any change in microdialysis conditions which might occur over time.

\section{RESULTS}

\section{MDMA and Stress Pretreatment on Basal Extracellular 5-HT Concentrations in VTA and Dopamine Concentrations in NAcc(sh)}

Pretreatment with MDMA followed by stress significantly decreased basal extracellular 5-HT in the VTA (Tukey's post hoc, $p<0.05)$ compared to stress alone (Figure 1). Pretreatment with MDMA produced an overall significant decrease in basal extracellular dopamine concentrations in the NAcc(sh) $\left(F_{1,21}=6.78, p<0.05\right)$ compared to saline groups (Figure 2). In contrast, there was no effect of stress on basal extracellular dopamine concentrations in either the saline or MDMA pretreated groups.

\section{MDMA and Stress Pretreatment on Extracellular 5-HT Concentrations in VTA after an MDMA Challenge}

An MDMA challenge ( $5 \mathrm{mg} / \mathrm{kg}$, i.p.) produced an overall increase in extracellular 5-HT concentrations in the VTA when analyzed across all MDMA groups and compared to 


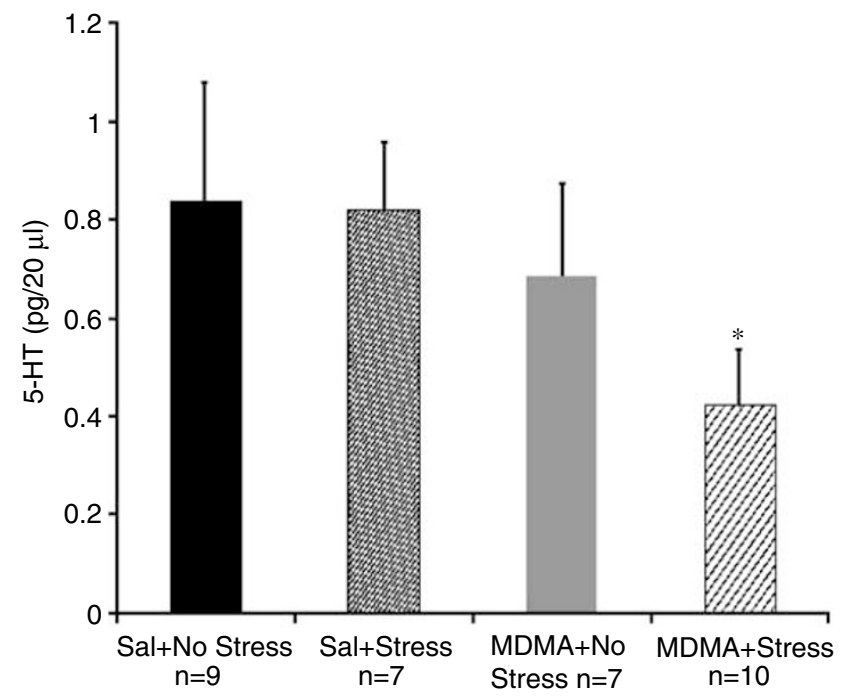

Figure I Basal extracellular concentrations of 5-HT in the VTA after pretreatment with saline, MDMA and/or chronic stress. Saline (Sal) or MDMA, $10 \mathrm{mg} / \mathrm{kg}$, every $2 \mathrm{~h} \times 4$ (i.p.) was injected 7 days before the start of CUS. Chronic stress was administered for 10 days before basal extracellular 5-HT was collected via microdialysis of the VTA. Bars represent an average of four baseline samples per rat after 17 days following pretreatment with drug and/or stress (7 days after saline or MDMA + 10 days of CUS/No CUS). $n=$ number of rats. Values are mean $\mathrm{pg} / 20 \mu \mathrm{l}$ of dialysate. ${ }^{*} p<0.05$ compared to Sal + stress treatment.

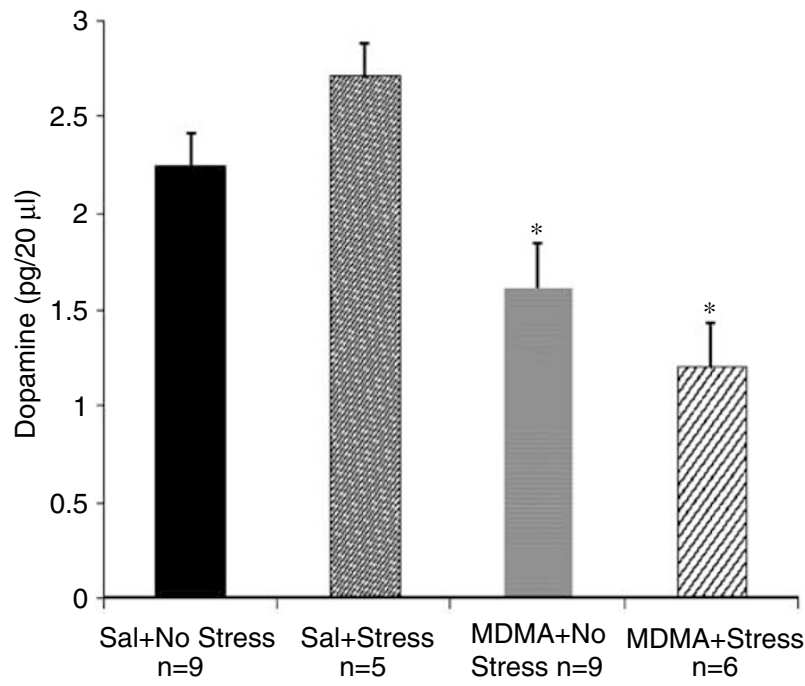

Figure 2 Basal extracellular concentrations of dopamine in $\mathrm{Nacc}(\mathrm{sh})$ after pretreatment with saline, MDMA and/or chronic stress. Saline (Sal) or MDMA, $10 \mathrm{mg} / \mathrm{kg}$, every $2 \mathrm{~h} \times 4$ (i.p.) was injected 7 days before the start of CUS. Chronic stress was administered for 10 days before basal extracellular DA was collected in the NAcc(sh) via microdialysis. Bars represent an average of four baseline samples per rat after 17 days following pretreatment with drug and/or stress (7 days after saline or MDMA + 10 days of CUS/No CUS). $n=$ number of rats. Values are mean $p g / 20 \mu$ of dialysate. $* p<0.05$ compared to saline treatments.

baseline concentrations $\left(\mathrm{F}_{2,52}=17.29, p<0.05\right)$ (Figure 3a). Pretreatment with MDMA + stress produced a maximal increase of $921 \%$ after a challenge injection of MDMA and the overall increase after an MDMA challenge was significantly greater than the MDMA + no stress and saline + stress groups (Tukey's post hoc, $p<0.05$ ).
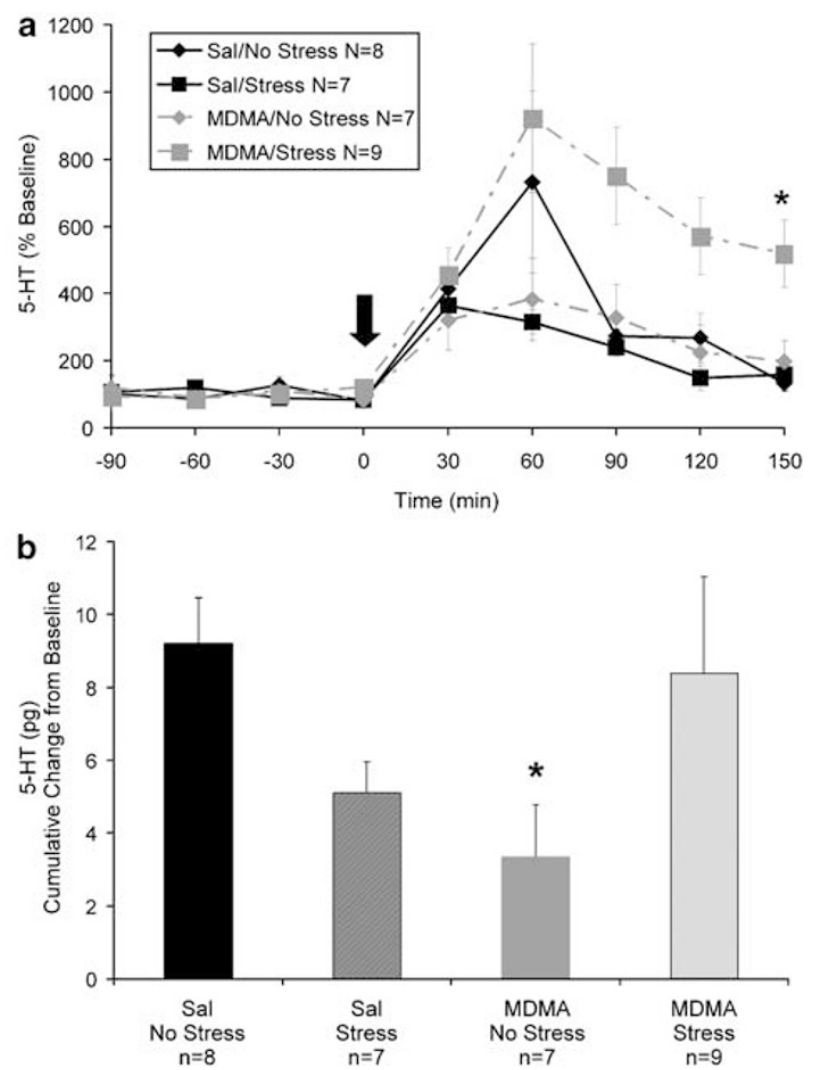

Figure 3 Extracellular 5-HT in the VTA before and after a challenge injection of MDMA. Dialysis samples were collected from the VTA of rats pretreated with saline (Sal) or MDMA $(10 \mathrm{mg} / \mathrm{kg}$, every $2 \mathrm{~h} \mathrm{~s} \times 4$, i.p.) and then 7 days later exposed to 10 days of CUS (stress). Experiments were performed after 17 days following pretreatment with drug and/or stress (7 days after saline or MDMA + 10 days of CUS/No CUS) (a) A challenge dose of MDMA (5 mg/kg, i.p.) was injected (as indicated by the black arrow) after a $2 \mathrm{~h}$ baseline. * $p<0.05$ compared to MDMA + no stress and saline + no stress pretreatment. (b) Mean cumulative picogram increase from the average of four baseline samples for $2.5 \mathrm{~h}$ after a challenge injection of MDMA. $* p<0.05$ compared to saline + no stress treatment.

When the overall effect of MDMA and/or stress during the $2.5 \mathrm{~h}$ following MDMA challenge is analyzed as a cumulative change from baseline (Figure $3 b$ ), there was a significant interaction effect between the pretreatment with MDMA and the pretreatment with stress $\left(\mathrm{F}_{1,27}=5.147\right.$, $p<0.05$ ) (Figure $3 b$ ). Stress had a differential effect on the total increase in 5-HT after a MDMA challenge such that stress tended to attenuate the increase in 5-HT in the saline pretreated group but restored the increase in the MDMA + stress pretreated group (Figure $3 b$ ).

\section{MDMA and Stress Pretreatment on Extracellular Dopamine Concentrations in NAcc(sh) after an MDMA Challenge}

An MDMA challenge $(5 \mathrm{mg} / \mathrm{kg})$ produced an increase in extracellular dopamine concentrations in the NAcc(sh) over baseline concentrations $\left(\mathrm{F}_{2,40}=35.31, p<0.05\right)$ (Figure 4). Pretreatment with MDMA + stress produced a maximal increase in dopamine of $1010 \%$ after the MDMA challenge that was significantly greater than the MDMA-induced increase in extracellular dopamine concentrations observed 


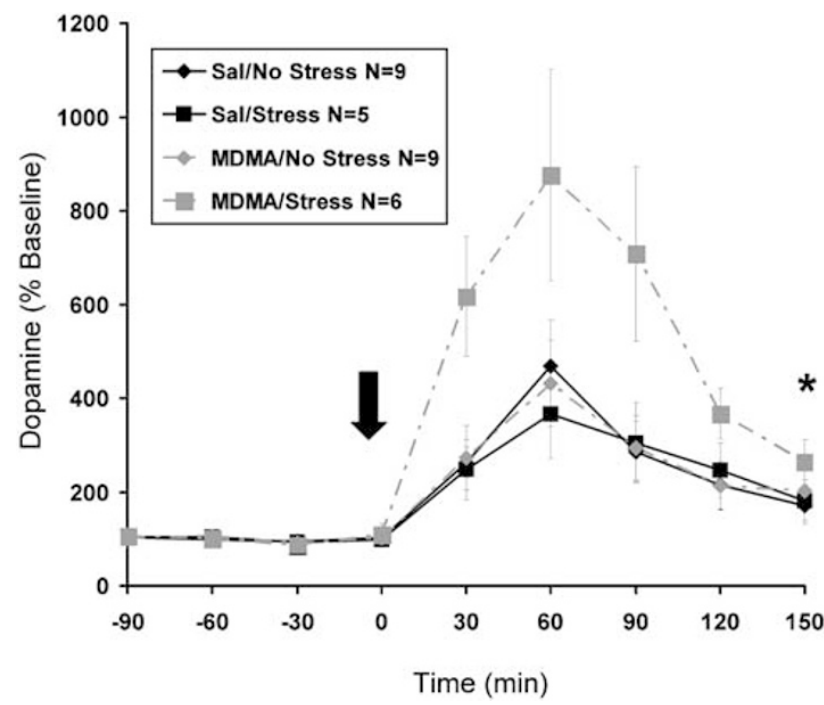

Figure 4 Extracellular dopamine in the NAcc(sh) before and after a challenge injection of MDMA. Dialysis samples were collected from the NAcc(sh) of rats pretreated with saline (Sal) or MDMA ( $10 \mathrm{mg} / \mathrm{kg}$, every $2 \mathrm{~h} \mathrm{~s} \times 4$, i.p.) and then 7 days later exposed to 10 days of CUS (stress). Experiments were performed after 17 days following pretreatment with drug and/or stress ( 7 days after saline or MDMA + 10 days of CUS/No CUS). A challenge dose of MDMA ( $5 \mathrm{mg} / \mathrm{kg}$, i.p.) was injected after a $2 \mathrm{~h}$ baseline (as indicated by the black arrow). ${ }^{*} p<0.05$ compared to all groups.

for any of the other pretreatment groups (Tukey's post hoc, $p<0.05)$.

\section{MDMA and Stress Pretreatment on Extracellular Dopamine Concentrations in NAcc(sh) after an MDMA Challenge: Effect of 5- $\mathrm{HT}_{1 \mathrm{~B}}$ Antagonism in VTA}

A challenge injection of MDMA to rats pretreated with MDMA + stress produced a cumulative increase during the $2.5 \mathrm{~h}$ following MDMA in extracellular dopamine in the $\mathrm{NAcc}(\mathrm{sh})$ to $22 \pm 3.7 \mathrm{pg}$ over baseline during the $2.5 \mathrm{~h}$ period after the MDMA challenge (Figure 5). GR127935 perfusion in the VTA of rats pretreated with MDMA + stress resulted in a mean increase above baseline to $4.9 \pm 2.0 \mathrm{pg} / 2.5 \mathrm{~h}$ in response to an MDMA challenge that was significantly less than the MDMA-induced increase in dopamine in the NAcc(sh) of rats pretreated with MDMA + stress (Tukey's post hoc, $p<0.05$ ) (Figure 5).

\section{5-HT and Dopamine Tissue Content in the NAcc after MDMA and Stress Pretreatment}

Pretreatment with MDMA ( $10 \mathrm{mg} / \mathrm{kg}$, every $2 \mathrm{~h} \times 4$, i.p.) produced a significant decrease in 5-HT tissue content in the NAcc when analyzed across both MDMA groups and compared to both saline groups $\left(\mathrm{F}_{1,66}=6.46, p<0.05\right)$ (Figure 6). Pretreatment with MDMA and/or stress did not produce a change in dopamine tissue content in the NAcc (Figure 7).

\section{DISCUSSION}

These results are the first to demonstrate that CUS after previous exposure to neurotoxic doses of MDMA

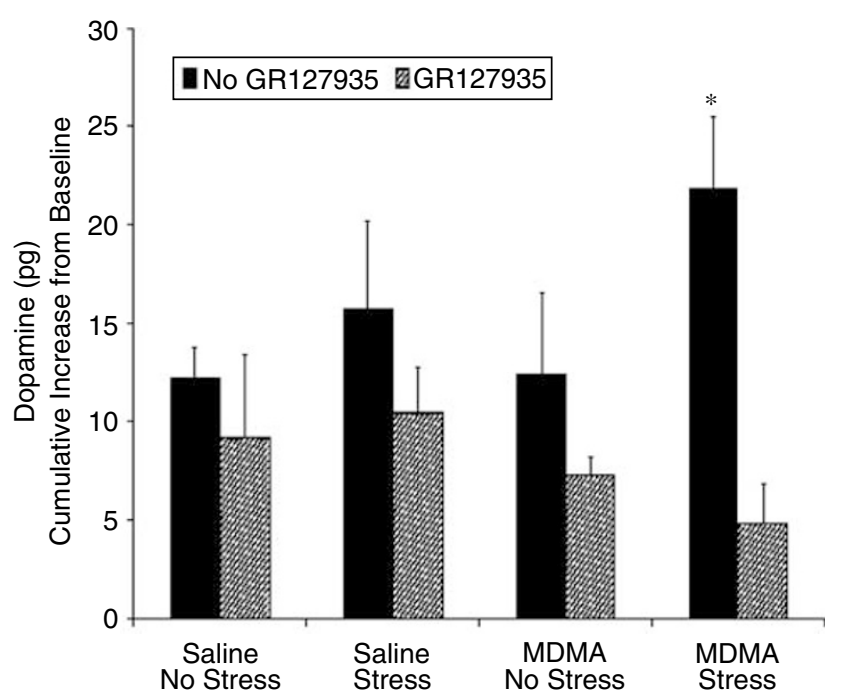

Figure 5 Effect of GRI27935 perfusion in VTA on MDMA-induced dopamine release after pretreatment with MDMA + chronic stress. Dialysis samples were collected from the NAcc(sh) of rats pretreated with saline or MDMA ( $10 \mathrm{mg} / \mathrm{kg}$, every $2 \mathrm{~h} \times 4$, i.p.) and then 7 days later treated with 10 days of CUS (stress) or no stress. Experiments were performed after 17 days following pretreatment with drug and/or stress ( 7 days after saline or MDMA + 10 days of stress/no stress). GRI27935 (I $\mu$ M) was reverse dialyzed into the VTA for I $\mathrm{h}$ before the challenge dose of MDMA $(5 \mathrm{mg} /$ $\mathrm{kg}$, i.p.) and continued for $2.5 \mathrm{~h}$. Values are mean cumulative picogram increase from the average of four baseline samples for $2.5 \mathrm{~h}$ after a challenge injection of MDMA. In No GRI27935 groups, $n=9$ for Sal + no stress, $n=5$ for Sal + stress, $n=9$ for MDMA + no stress, $n=6$ for MDMA + stress; In GRI27935 groups, $n=5$ for Sal + no stress, $n=7$ for Sal + stress, $n=5$ for MDMA + no stress, $n=4$ for MDMA + stress. $* p<0.05$ compared to MDMA + stress with GRI27935 treatment.

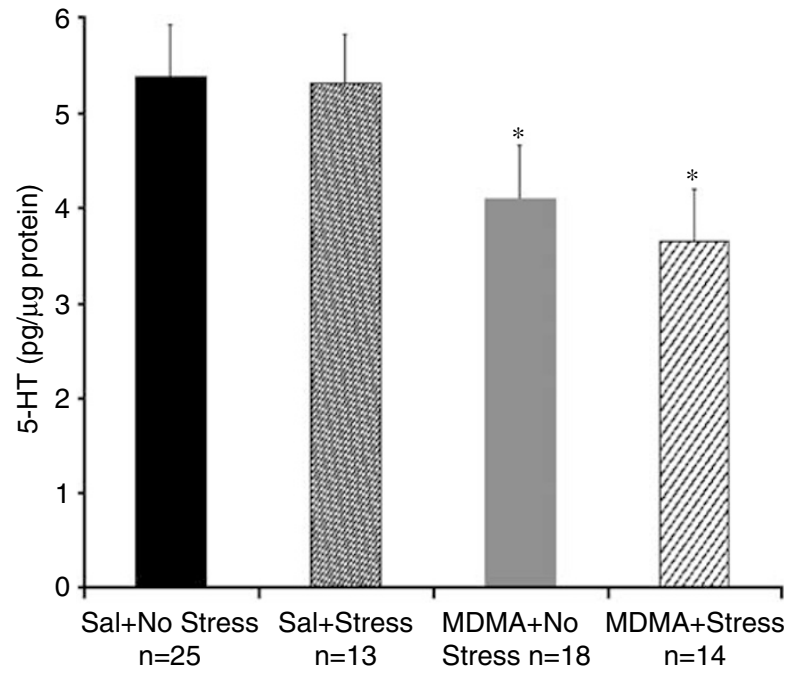

Figure $65-\mathrm{HT}$ content in the NAcc after pretreatment with saline or MDMA and chronic stress (stress) or no stress. Rats were killed 3 weeks after pretreatment with saline (Sal) or MDMA $(10 \mathrm{mg} / \mathrm{kg}$, every $2 \mathrm{~h} \times 4$, i.p.) followed by stress/no stress. $* p<0.05$ compared to saline groups.

alters basal and MDMA-stimulated mesolimbic dopamine and 5-HT release, and suggest that stress can alter the neuronal mechanisms associated with MDMA reward and abuse. Neurotoxic MDMA followed by stress produced a 


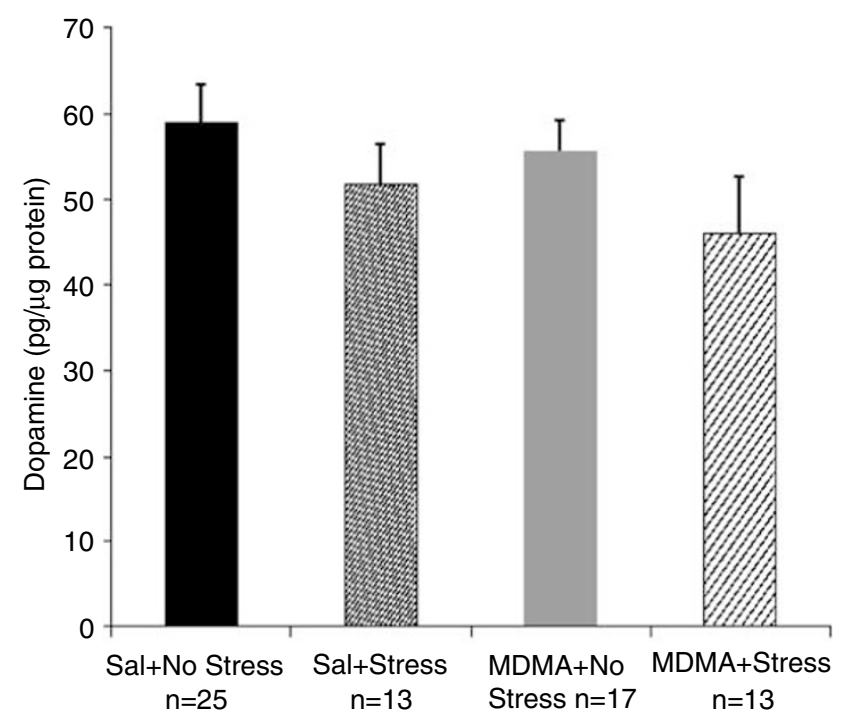

Figure 7 Dopamine content in the NAcc after pretreatment with saline or MDMA and chronic stress (stress) or no stress. Rats were killed 3 weeks after pretreatment with saline (Sal) or MDMA $(10 \mathrm{mg} / \mathrm{kg}$, every $2 \mathrm{~h} \times 4$, i.p.) followed by stress/no stress.

significant reduction of baseline extracellular 5-HT in the VTA and dopamine in NAcc shell (NAcc(sh)) (Figures 1 and 2). In contrast, MDMA-induced dopamine efflux in the NAcc(sh) was enhanced by the combined pretreatments with neurotoxic MDMA and chronic stress (Figure 4). Overall, these data show that pre-exposure to MDMA and stress is not simply additive but synergize to augment mesolimbic dopamine neurotransmission in a manner that is both quantitatively and qualitatively different from either the effects of MDMA or stress alone. Furthermore, stress exposure after a neurotoxic regimen of MDMA did not affect the neurotoxicty of MDMA as indicated by the unaltered long-term depletion of 5-HT tissue content (Figure 6). Thus, the effects of stress exposure after MDMA are not the result of added damage to 5-HT that is produced by MDMA.

Neurotoxic MDMA, either alone or followed by stress, decreased the basal release of dopamine in the nACC shell (Figure 2). In contrast, pretreatment with stress did not affect basal extracellular dopamine concentrations regardless of drug pretreatment. The reduced basal extracellular dopamine concentrations in the MDMA + stress group may be secondary to MDMA-induced damage to 5-HT neurons, depletion of tissue 5-HT content, and a consequent reduction in the activation of $5-\mathrm{HT}_{1 \mathrm{~B}}$ receptors in the VTA (Yan et al, 2004; Yan and Yan, 2001a). This possibility is consistent with the lower basal extracellular 5-HT observed after neurotoxic doses of MDMA followed by stress (Figure 1). However, it remains unclear how neurotoxic MDMA alone reduced basal dopamine but had no effect on basal 5-HT. Therefore, a neurotoxic regimen of MDMA lowers basal extracellular dopamine concentrations in a manner independent of changes in basal 5-HT concentrations. In fact, repeated doses of the non-neurotoxic stimulant cocaine (Zhang et al, 2003) or low, nontoxic doses of methamphetamine (Broom and Yamamoto, 2005) also lower basal dopamine release in the NAcc(sh). This effect may be an adaptive response to psychostimulant drugs resulting from an upregulation of accumbal dopamine transporter expression (Broom and Yamamoto, 2005) and suggests that long-term changes in stimulant-induced decreases in basal extracellular dopamine are due to enhanced reuptake of dopamine from the extracellular space.

In contrast to the reduced basal extracellular concentrations of dopamine which appear to be linked to neurotoxic MDMA treatment, a reduction in basal 5-HT in the VTA occurs only after the pretreatment with MDMA and stress. Other studies have reported decreased basal 5-HT release in hippocampus after MDMA (Matuszewich et al, 2002) or chronic stress (Mangiavacchi et al, 2001). The present studies demonstrating decreased basal 5-HT release only after both MDMA and stress indicates a synergistic diminution of extracellular 5-HT in the VTA. It can be speculated that one contributory factor may be a stressinduced reduction in the vesicular monoamine transporter2 (VMAT-2) (Zucker et al, 2005) resulting in decreased filling of 5-HT vesicles (Pothos et al, 2000; Fon et al, 1997). This reduction of VMAT-2 and 5-HT quantal size may decrease basal release to a greater degree in neurons previously compromised by MDMA, particularly since neurotoxic amphetamines have also been shown to reduce VMAT-2 (Hansen et al, 2002; Eyerman and Yamamoto, 2005; Frey et al, 1997). Regardless, further studies are necessary to examine the impact of stress and MDMA on VMAT2 as one of several mechanisms that are likely contributors to the observed decrease in basal 5-HT. It is also important to note that the present results of dialysate concentrations of monoamines, unlike those collected with no-net-flux microdialysis, does not measure actual concentrations of neurotransmitters in the extracellular space of the brain.

Neurotoxic MDMA alone produced a significant reduction in MDMA-induced release of 5-HT (Figure 3). This finding is consistent with similar studies in the striatum (Shankaran and Gudelsky, 1999) and suggests that MDMAinduced damage to 5-HT terminals is sufficient to limit transporter-mediated release. Surprisingly, when analyzed as a cumulative increase from baseline (Figure $3 \mathrm{~b}$ ), there was a more pronounced increase in MDMA-stimulated release of 5-HT in rats pretreated with MDMA and stress compared to rats pretreated with MDMA alone (MDMA + no stress). Further studies are needed to determine if stress actually ameliorates MDMA-induced deficits in stimulated 5-HT release. However, when the lower basal extracellular 5-HT concentrations of the neurotoxic MDMA+stress group are considered, the relative increase from basal 5-HT concentrations is the greatest of all the conditions examined. Thus, the combination of neurotoxic MDMA followed by stress produced a relative greater increase in MDMA-induced 5-HT than either MDMA or stress alone. Neurotoxic doses of MDMA followed by chronic stress also appeared to delay the return of VTA 5-HT levels to baseline, suggesting that MDMA followed by stress enhances both the relative 5-HT response to an MDMA challenge as well as the duration of the response. Moreover, the large relative change from baseline VTA 5-HT observed in the MDMA + stress group corresponds to a greatly enhanced dopamine release in the NAcc(sh) (Figure 4) and suggests that mesolimbic dopamine release may be more responsive to relative rather than absolute changes in 5-HT. 
Another factor which may account for the enhanced relative release of 5-HT after the combination of MDMA and stress may be a decreased $5-\mathrm{HT}_{1 \mathrm{~A}}$ autoreceptormediated inhibition of raphe neuron firing rate (Sprouse and Aghajanian, 1987; Sotelo et al, 1990). Neurotoxic doses of MDMA (Aguirre et al, 1995) or chronic stress (Laaris et al, 1997; Lanfumey et al, 1999) decrease $5-\mathrm{HT}_{1 \mathrm{~A}}$ receptor activity. Under normal conditions, MDMA stimulated 5-HT release would act at $5-\mathrm{HT}_{1 \mathrm{~A}}$ autoreceptors to inhibit cell firing rates. However, pretreatment with neurotoxic doses of MDMA and exposure to chronic stress may reduce or eliminate $5-\mathrm{HT}_{1 \mathrm{~A}}$ receptor-mediated autoinhibition of $5-\mathrm{HT}$ neurons. The resultant continued firing of 5-HT neurons would enhance the calcium-dependent component of MDMA-induced 5-HT release (Azmitia et al, 1990; Crespi et al, 1997), and together with MDMA-induced reductions in SERT (Battaglia et al, 1987), could be sufficient to reverse the deficits in MDMA-induced 5-HT release observed after neurotoxic MDMA or stress alone.

MDMA + stress pretreatment produced a dramatic increase in MDMA-induced dopamine release in the NAcc(sh). The lack of effect observed with either treatment alone clearly demonstrates a synergism between the combined effects of MDMA and stress pretreatments to enhance MDMA-induced dopamine (Figure 4). It is interesting to note that this effect was blocked by the perfusion of the 5- $\mathrm{HT}_{1 \mathrm{~B}}$ receptor antagonist GR 127935 (de Vries et al, 1997) into the VTA (Figure 5). This finding is consistent with the conclusion that $5-\mathrm{HT}_{1 \mathrm{~B}}$ receptor activation is required for the MDMA + stress enhancement of accumbal dopamine release and is supported by studies showing that $5-\mathrm{HT}_{1 \mathrm{~B}}$ activation in the VTA can disinhibit dopamine neurons (Yan et al, 2005; Yan and Yan, 2001a) via a reduction of local GABA release (Yan and Yan, 2001b; Yan et al, 2004).

$5-\mathrm{HT}_{2 \mathrm{C}}$ receptors are thought to oppose $5-\mathrm{HT}_{1 \mathrm{~B}}$ receptors and inhibit mesolimbic DA (De Deurwaerdere et al, 2004; Di Giovanni et al, 2000; Di Matteo et al, 1999). We have shown that blockade of $5-\mathrm{HT}_{2 \mathrm{C}}$ receptors in the VTA inhibits local GABA release while simultaneously enhancing MDMAinduced dopamine release in NAcc(sh) (Bankson and Yamamoto, 2004). Therefore, the present data demonstrating enhanced $5-\mathrm{HT}_{1 \mathrm{~B}}$-dependent mesolimbic dopamine efflux after a challenge dose of MDMA are consistent with a relative increase of $5-\mathrm{HT}_{1 \mathrm{~B}}$ over $5-\mathrm{HT}_{2 \mathrm{C}}$ receptor function. It remains to be seen if the enhanced $5-\mathrm{HT}_{1 \mathrm{~B}}$ response to an MDMA challenge is the result of $5-\mathrm{HT}_{1 \mathrm{~B}}$ receptor sensitization due to the lower basal extracellular concentrations of $5-\mathrm{HT}$ noted in this group. Regardless, increased $5-\mathrm{HT}_{1 \mathrm{~B}}$ or decreased 5- $\mathrm{HT}_{2 \mathrm{C}}$ activation in the VTA should result in an enhanced accumbal dopamine response via decreased GABA release in the VTA (Bankson and Yamamoto, 2004; Yan and Yan, 2001b). The role of 5- $\mathrm{HT}_{2 \mathrm{C}}$ or other receptors is unknown, but prevention of the enhanced MDMAinduced dopamine release by GR 127935 demonstrates that $5-\mathrm{HT}_{1 \mathrm{~B}}$ receptor activation is necessary for the synergistic increase in accumbal dopamine release produced by the pretreatment of MDMA and chronic stress.

A common feature of MDMA (Cadoni et al, 2005; Bankson and Yamamoto, 2004) and other drugs of abuse is their ability to elevate extracellular dopamine in the shell region of the nACC. This elevation of NAcc(sh) dopamine is widely accepted as the basis for drug-induced reward (Wise and Bozarth, 1984; Wise, 1984; Hoebel, 1985; Koob and Weiss, 1992; Carlezon and Wise, 1996; Everitt et al, 1999; Di Chiara and Imperato, 1988). Conversely, disruption of dopamine transmission attenuates the rewarding effects of MDMA in rats trained to self-administer MDMA (Daniela et $a l$, 2004). Therefore, the enhanced MDMA-induced dopamine efflux observed after previous exposure to MDMA + chronic stress could reflect an increase in the rewarding and addictive properties of MDMA. The lower basal extracellular dopamine observed after MDMA and stress may also facilitate and sustain drug-seeking behavior. Reduced basal extracellular dopamine concentrations in the NAcc triggers drug-seeking behavior in animals trained to self-administer stimulants and is thought to represent drug craving (Gratton and Wise, 1994; Wise, 1994; Wise et al, 1995; Gerrits et al, 2002). Thus, the combination of neurotoxic MDMA followed by chronic stress may exacerbate craving and drug-seeking behavior as well as enhance the rewarding and addictive properties of MDMA or other addictive drugs.

In conclusion, prior exposure to a neurotoxic regimen of MDMA followed by CUS may enhance the rewarding and addictive properties of MDMA or other drugs through changes in mesolimbic monoamine transmission, which are quantitatively and qualitatively different from the effects of either treatment alone. The enhanced dopamine release observed in the NAcc(sh) after pre-exposure to MDMA and chronic stress is dependent upon $5-\mathrm{HT}_{1 \mathrm{~B}}$ activation in the VTA and implicates this receptor as a new critical mediator of chronic stress-induced changes in the neurophysiological and behavioral effects of MDMA.

\section{ACKNOWLEDGEMENTS}

This work was supported by DA 16866, DA16501, and a gift from Hitachi America Inc.

\section{REFERENCES}

Abercrombie ED, Keefe KA, DiFrischia DS, Zigmond MJ (1989). Differential effect of stress on in vivo dopamine release in striatum, nucleus accumbens, and medial frontal cortex. J Neurochem 52: 1655-1658.

Aguirre N, Galbete JL, Lasheras B, Del RJ (1995). Methylenedioxymethamphetamine induces opposite changes in central preand postsynaptic 5-HT1A receptors in rats. Eur J Pharmacol 281: 101-105.

Azmitia EC, Murphy RB, Whitaker-Azmitia PM (1990). MDMA (ecstasy) effects on cultured serotonergic neurons: evidence for Ca2(+)-dependent toxicity linked to release. Brain Res 510: 97-103.

Bankson MG, Yamamoto BK (2004). Serotonin-GABA interactions modulate MDMA-induced mesolimbic dopamine release. J Neurochem 91: 852-859.

Battaglia G, Yeh SY, O'Hearn E, Molliver ME, Kuhar MJ, de Souza EB (1987). 3,4-Methylenedioxymethamphetamine and 3,4methylenedioxyamphetamine destroy serotonin terminals in rat brain: quantification of neurodegeneration by measurement of [3 H]paroxetine-labeled serotonin uptake sites. J Pharmacol Exp Ther 242: 911-916.

Bielajew C, Konkle AT, Merali Z (2002). The effects of chronic mild stress on male Sprague-Dawley and Long-Evans rats. I. 
Biochemical and physiological analyses. Behav Brain Res 136: 583-593.

Bland ST, Twining C, Watkins LR, Maier SF (2003). Stressor controllability modulates stress-induced serotonin but not dopamine efflux in the nucleus accumbens shell. Synapse 49: 206-208.

Broom SL, Yamamoto BK (2005). Effects of subchronic methamphetamine exposure on basal dopamine and stress-induced dopamine release in the nucleus accumbens shell of rats. Psychopharmacology (Berlin) 181: 467-476.

Cadoni C, Solinas M, Pisanu A, Zernig G, Acquas E, Di CG (2005). Effect of 3,4-methylendioxymethamphetamine (MDMA, 'ecstasy') on dopamine transmission in the nucleus accumbens shell and core. Brain Res 1055: 143-148.

Cameron DL, Williams JT (1994). Cocaine inhibits GABA release in the VTA through endogenous 5-HT. J Neurosci 14: 6763-6767.

Cameron DL, Williams JT (1995). Opposing roles for dopamine and serotonin at presynaptic receptors in the ventral tegmental area. Clin Exp Pharmacol Physiol 22: 841-845.

Carlezon Jr WA, Wise RA (1996). Rewarding actions of phencyclidine and related drugs in nucleus accumbens shell and frontal cortex. J Neurosci 16: 3112-3122.

Crespi D, Mennini T, Gobbi M (1997). Carrier-dependent and $\mathrm{Ca}(2+)$-dependent 5-HT and dopamine release induced by (+)amphetamine, 3,4-methylendioxymethamphetamine, p-chloroamphetamine and (+)-fenfluramine. Br J Pharmacol 121: $1735-1743$.

Daniela E, Brennan K, Gittings D, Hely L, Schenk S (2004). Effect of SCH 23390 on (+/-)-3,4-methylenedioxymethamphetamine hyperactivity and self-administration in rats. Pharmacol Biochem Behav 77: 745-750.

De Deurwaerdere P, Navailles S, Berg KA, Clarke WP, Spampinato U (2004). Constitutive activity of the serotonin 2C receptor inhibits in vivo dopamine release in the rat striatum and nucleus accumbens. J Neurosci 24: 3235-3241.

de Vries P, Apaydin S, Villalon CM, Heiligers JP, Saxena PR (1997). Interactions of GR127935, a 5-HT(1B/D) receptor ligand, with functional 5-HT receptors. Naunyn Schmiedebergs Arch Pharmacol 355: 423-430.

Di Chiara G, Imperato A (1988). Drugs abused by humans preferentially increase synaptic dopamine concentrations in the mesolimbic system of freely moving rats. Proc Natl Acad Sci USA 85: 5274-5278.

Di Giovanni G, Di Matteo V, Di Mascio M, Esposito E (2000). Preferential modulation of mesolimbic $v s$ nigrostriatal dopaminergic function by serotonin $(2 \mathrm{C} / 2 \mathrm{~B})$ receptor agonists: a combined in vivo electrophysiological and microdialysis study. Synapse 35: 53-61.

Di Matteo V, Di Giovanni G, Di Mascio M, Esposito E (1999). SB 242084, a selective serotonin $2 \mathrm{C}$ receptor antagonist, increases dopaminergic transmission in the mesolimbic system. Neuropharmacology 38: 1195-1205.

Doherty MD, Pickel VM (2000). Ultrastructural localization of the serotonin $2 \mathrm{~A}$ receptor in dopaminergic neurons in the ventral tegmental area. Brain Res 864: 176-185.

Everitt BJ, Parkinson JA, Olmstead MC, Arroyo M, Robledo P, Robbins TW (1999). Associative processes in addiction and reward. The role of amygdala-ventral striatal subsystems. Ann NY Acad Sci 877: 412-438.

Eyerman DJ, Yamamoto BK (2005). Lobeline attenuates methamphetamine-induced changes in vesicular monoamine transporter 2 immunoreactivity and monoamine depletions in the striatum. J Pharmacol Exp Ther 312: 160-169.

Fon EA, Pothos EN, Sun BC, Killeen N, Sulzer D, Edwards RH (1997). Vesicular transport regulates monoamine storage and release but is not essential for amphetamine action. Neuron 19: 1271-1283.
Frey K, Kilbourn M, Robinson T (1997). Reduced striatal vesicular monoamine transporters after neurotoxic but not after behaviorally-sensitizing doses of methamphetamine. Eur J Pharmacol 334: 273-279.

Gerrits MA, Petromilli P, Westenberg HG, Di CG, van Ree JM (2002). Decrease in basal dopamine levels in the nucleus accumbens shell during daily drug-seeking behaviour in rats. Brain Res 924: 141-150.

Gervais J, Rouillard C (2000). Dorsal raphe stimulation differentially modulates dopaminergic neurons in the ventral tegmental area and substantia nigra. Synapse 35: 281-291.

Gratton A, Wise RA (1994). Drug- and behavior-associated changes in dopamine-related electrochemical signals during intravenous cocaine self-administration in rats. J Neurosci 14: $4130-4146$

Gudelsky GA, Nash JF (1996). Carrier-mediated release of serotonin by 3,4-methylenedioxymethamphetamine: implications for serotonin-dopamine interactions. J Neurochem 66: 243-249.

Haile CN, GrandPre T, Kosten TA (2001). Chronic unpredictable stress but not predictable stress, enhances the sensitivity to the behavioral effects of cocaine in rats. Psychopharmacology 154: 213-220.

Hansen JP, Riddle EL, Sandoval V, Brown JM, Gibb JW, Hanson GR et al (2002). Methylenedioxymethamphetamine decreases plasmalemmal and vesicular dopamine transport: mechanisms and implications for neurotoxicity. J Pharmacol Exp Ther 300: $1093-1100$

Herman JP, Adams D, Prewitt C (1995). Regulatory changes in neuroendocrine stress-integrative circuitry produced by a variable stress paradigm. Neuroendocrinology 61: 180-190.

Hoebel BG (1985). Brain neurotransmitters in food and drug reward. Am J Clin Nutr 42: 1133-1150.

Johnson MP, Conarty PF, Nichols DE (1991). [ $\left.{ }^{3} \mathrm{H}\right]$ monoamine releasing and uptake inhibition properties of 3,4-methylenedioxymethamphetamine and p-chloroamphetamine analogues. Eur J Pharmacol 200: 9-16.

Kalivas PW, Duffy P (1995). Selective activation of dopamine transmission in the shell of the nucleus accumbens by stress. Brain Res 675: 325-328.

Katz RJ, Roth KA, Carroll BJ (1981). Acute and chronic stress effects on open field activity in the rat: implications for a model of depression. Neurosci Biobehav Rev 5: 247-251.

Koch S, Galloway MP (1997). MDMA induced dopamine release in vivo: role of endogenous serotonin. J Neural Transm 104: 135-146.

Koob GF (1992). Drugs of abuse: anatomy, pharmacology and function of reward pathways. Trends Pharmacol Sci 13: 177-184.

Koob GF, Weiss F (1992). Neuropharmacology of cocaine and ethanol dependence. Recent Dev Alcohol 10: 201-233.

Kosten TR, Rounsaville BJ, Kleber HD (1986). A 2.5 year follow-up of depression, life crises, and treatment effects on abstinence among opioid addicts. Arch Gen Psychiatry 43: 733-738.

Laaris N, Le PE, Hamon M, Lanfumey L (1997). Stress-induced alterations of somatodendritic 5-HT1A autoreceptor sensitivity in the rat dorsal raphe nucleus-in vitro electrophysiological evidence. Fundam Clin Pharmacol 11: 206-214.

Lanfumey L, Pardon MC, Laaris N, Joubert C, Hanoun N, Hamon $\mathrm{M}$ et al (1999). 5-HT1A autoreceptor desensitization by chronic ultramild stress in mice. Neuroreport 10: 3369-3374.

Lopez JF, Chalmers DR, Little KY, Watson SJ (1998). Rsuglatino of serotoninlA, glucocorticoid, and mineralocorticoid receptor in rat and human hippocampus: implications for the neurobiology of depression. Biol Psychiatry 43: 547-573.

Mangiavacchi S, Masi F, Scheggi S, Leggio B, De Montis MG, Gambarana C (2001). Long-term behavioral and neurochemical effects of chronic stress exposure in rats. J Neurochem 79: $1113-1121$ 
Matuszewich L, Filon ME, Finn DA, Yamamoto BK (2002). Altered forebrain neurotransmitter responses to immobilization stress following 3,4-methylenedioxymethamphetamine. Neuroscience 110: $41-48$.

Matuszewich L, Yamamoto BK (2003). Long-lasting effects of chronic stress on DOI-induced hyperthermia. Psychopharmaco$\log y$ 169: 169-175.

McCreary AC, Bankson MG, Cunningham KA (1999). Pharmacological studies of the acute and chronic effects of (+)-3, 4-methylenedioxymethamphetamine on locomotor activity: role of 5-hydroxytryptamine(1A) and 5-hydroxytryptamine(1B/1D) receptors. J Pharmacol Exp Ther 290: 965-973.

Morley KC, Cornish JL, Li KM, McGregor IS (2004). Preexposure to MDMA ('Ecstasy') delays acquisition but facilitates MDMAinduced reinstatement of amphetamine self-administration behavior in rats. Pharmacol Biochem Behav 79: 331-342.

Najavits LM, Gastfriend DR, Barber JP, Reif S, Muenz LR, Blaine J et al (1998). Cocaine dependence with and without PTSD among subjects in the National Institute on Drug Abuse Collaborative Cocaine Treatment Study. Am J Psychiatry 155: 214-219.

O'Dell LE, Parsons LH (2004). Serotonin1B receptors in the ventral tegmental area modulate cocaine-induced increases in nucleus accumbens dopamine levels. J Pharmacol Exp Ther 311: 711-719.

O'Hearn E, Battaglia G, de Souza EB, Kuhar MJ, Molliver ME (1988). Methylenedioxyamphetamine (MDA) and methylenedioxymethamphetamine (MDMA) cause selective ablation of serotonergic axon terminals in forebrain: immunocytochemical evidence for neurotoxicity. J Neurosci 8: 2788-2803.

Ortiz J, Fitzgerald LW, Lane S, Terwilliger R, Nestler E (1996). Biochemical adaptations in the mesolimbic dopamine system in response to repeated stress. Neuropsychopharmacology 14: 433-452.

Piazza PV, Le MM (1998). The role of stress in drug selfadministration. Trends Pharmacol Sci 19: 67-74.

Pothos EN, Larsen KE, Krantz DE, Liu Y, Haycock JW, Setlik W et al (2000). Synaptic vesicle transporter expression regulates vesicle phenotype and quantal size. J Neurosci 20: 7297-7306.

Rhoads DL (1983). A longitudinal study of life stress and social support among drug abusers. Int J Addict 18: 195-222.

Scearce-Levie K, Viswanathan SS, Hen R (1999). Locomotor response to MDMA is attenuated in knockout mice lacking the 5-HT1B receptor. Psychopharmacology (Berlin) 141: 154-161.

Schmidt CJ (1987). Neurotoxicity of the psychedelic amphetamine, methylenedioxymethamphetamine. J Pharmacol Exp Ther 240: $1-7$.

Schmidt CJ, Taylor VL (1988). Direct central effects of acute methylenedioxymethamphetamine on serotonergic neurons. Eur J Pharmacol 156: 121-131.

Series HG, Cowen PJ, Sharp T (1994). p-Chloroamphetamine (PCA), 3,4-methylenedioxy-methamphetamine (MDMA) and $\mathrm{d}$-fenfluramine pretreatment attenuates d-fenfluramine-evoked release of 5-HT in vivo. Psychopharmacology (Berlin) 116: 508-514.

Shankaran M, Gudelsky GA (1999). A neurotoxic regimen of MDMA suppresses behavioral, thermal and neurochemical responses to subsequent MDMA administration. Psychopharmacology (Berlin) 147: 66-72.
Sotelo C, Cholley B, El MS, Gozlan H, Hamon M (1990). Direct immunohistochemical evidence of the existence of 5-HT1A autoreceptors on serotoninergic neurons in the midbrain raphe nuclei. Eur J Neurosci 2: 1144-1154.

Sprouse JS, Aghajanian GK (1987). Electrophysiological responses of serotoninergic dorsal raphe neurons to 5-HT1A and 5-HT1B agonists. Synapse 1: 3-9.

Willner P, Puscat R, Papp M (1992). Chronic mild stress-induced anhedonia: a realistic animal model of depression. Neurosci Biobehav Rev 16: 525-534.

Wilsnack SC, Vogeltanz ND, Klassen AD, Harris TR (1997). Childhood sexual abuse and women's substance abuse: national survey findings. J Stud Alcohol 58: 265-271.

Wise RA, Bozarth MA (1984). Brain reward circuitry: four circuit elements 'wired' in apparent series. Brain Res Bull 12: 203-208.

Wise RA (1984). Neural mechanisms of the reinforcing action of cocaine. NIDA Res Monogr 50: 15-33.

Wise RA, Bozarth MA (1985). Brain mechanisms of drug reward and euphoria. Psychiatr Med 3: 445-460.

Wise RA (1994). Cocaine reward and cocaine craving: the role of dopamine in perspective. NIDA Res Monogr 145: 191-206.

Wise RA, Newton P, Leeb K, Burnette B, Pocock D, Justice Jr JB (1995). Fluctuations in nucleus accumbens dopamine concentration during intravenous cocaine self-administration in rats. Psychopharmacology (Berlin) 120: 10-20.

Yamamoto BK, Nash JF, Gudelsky GA (1995). Modulation of methylenedioxymethamphetamine-induced striatal dopamine release by the interaction between serotonin and gammaaminobutyric acid in the substantia nigra. J Pharmacol Exp Ther 273: 1063-1070.

Yamamoto BK, Pehek EA (1990). A functional heterogeneity of the rat striatum as measured by in vivo electrochemistry and microdialysis. Brain Research 506: 236-242.

Yan QS, Yan SE (2001a). Serotonin-1B receptor-mediated inhibition of $[(3) \mathrm{H}] \mathrm{GABA}$ release from rat ventral tegmental area slices. J Neurochem 79: 914-922.

Yan QS, Yan SE (2001b). Activation of 5-HT(1B/1D) receptors in the mesolimbic dopamine system increases dopamine release from the nucleus accumbens: a microdialysis study. Eur $J$ Pharmacol 418: 55-64.

Yan QS, Zheng SZ, Yan SE (2004). Involvement of 5-HT1B receptors within the ventral tegmental area in regulation of mesolimbic dopaminergic neuronal activity via GABA mechanisms: a study with dual-probe microdialysis. Brain Res 1021: 82-91.

Yan QS, Zheng SZ, Feng MJ, Yan SE (2005). Involvement of 5 -HT1B receptors within the ventral tegmental area in ethanolinduced increases in mesolimbic dopaminergic transmission. Brain Res 1060: 126-137.

Zhang Y, Schlussman SD, Ho A, Kreek MJ (2003). Effect of chronic 'binge cocaine' on basal levels and cocaine-induced increases of dopamine in the caudate putamen and nucleus accumbens of C57BL/6J and 129/J mice. Synapse 50: 191-199.

Zucker M, Weizman A, Rehavi M (2005). Repeated swim stress leads to down-regulation of vesicular monoamine transporter 2 in rat brain nucleus accumbens and striatum. Eur Neuropsychopharmacol 15: 199-201. 